\title{
Planning and Presenting an NCLA Workshop: the 2006 RTSS Spring Workshop Experience
}

\author{
Elizabeth Cramer*
}

$\mathrm{P}$ lanning and presenting workshops, particularly in nonconference years, are two of the main responsibilities of every NCLA Section. The workshops serve several purposes; they provide continuing education opportunities, create state-wide networking opportunities, ensure NCLA Section members that their membership dues are working for them, and help to attract new members.

One of my main goals as Chair of the NCLA Resources and Technical Services Section was to resurrect the biannual RTSS Spring Workshop. To best serve the library technical services staff throughout the state and to meet our economic expectations, we chose a conference facility in the center of the state and succeeded in meeting our attendance goal of 100 participants. The workshop lasted from 10:00 a.m. to 3:30 p.m. (including lunch) and included three tracts of programming with seven separate programs in all. Planning and presenting such an undertaking was time-consuming because of the many details, big and small. Since none of our Executive Board members had ever planned such an event we were successful mainly due to the guidance of the NCLA Administrative Assistant, the NCLA Treasurer, and common sense.

This is not meant to be an exhaustive list for workshop planning nor is it an official publication of NCLA. It is my attempt to document RTSS's experience in planning and presenting an NCLA Section Workshop and offering this information to other NCLA sections in the hope that it will help them in creating and presenting successful workshops.

\section{Getting Started: Programming Ideas for your Workshop}

- Brainstorm with your section's Executive Board for program ideas.

- Poll section members to discover what programming they would like or need.

- If finances allow, contact professional consultants. Solinet offered three presentations at our Spring Workshop, all meaty and specific.

- Divide program responsibilities among the members of the section executive board or section members. For our RTSS Spring Workshop each executive board member was responsible for planning and coordinating one program.

- Vary your programs to meet the diverse needs of your potential audience. We created programs for each of the RTSS subsections: Cataloging, Serials, Collection Development, and Acquisitions. We also included programs that were useful and specific to paraprofessionals.

\footnotetext{
* Catalog Librarian, Belk Library \& Information Commons, Boone, NC
}

Site selection

- Ask other librarians in the state for suggestions. We received informative feedback from the State Library of North Carolina, NCLA Executive Board members, and chairs of other NCLA sections.

- Consult with your section members. Section members may help you to arrange for free use of their organization's conference facilities.

- Create a list of facility needs and ask if they can be met. Examples include projectors, screens, computers (with appropriate software), podiums, seating capacity requirements, dining facilities, registration table. Ask if there is an extra charge for such items.

- Plan a site visit before signing a contract.

- If event is to be catered, ask to see a sample lunch or at least have it described over the phone. Often you have no choice of who caters the event; caterers are contracted by the facility.

\section{Registration and Publicity}

- We designed brochures which included place, time, location, registration fee, a brief description of the workshop, a registration form, directions, and deadline for registration. Be sure to include a space for credit card numbers and signature.

- Mail out paper copies to appropriate persons. We chose to mail out a paper copy to all RTSS members and handed out copies at the NCLA Executive Board quarterly meeting.

- Post an electronic copy of the brochure/registration form on your section's NCLA Web site.

- Send out the brochure/registration form as an attachment on the NCLA LISTSERV.

- Have financial goals in mind. Do you hope to break even after the workshop? Will you want to cancel the workshop if you have an insufficient number of registrants? What is the NCLA policy on event refunds?

\section{Finances}

- Know your budget and projected financial outcome in advance.

- If a down payment is required for facility reservation, catering, or instructional services, mail or fax a copy of the contract with the NCLA check payment form (included in the NCLA Handbook and online at www.nclaonline.org) to the NCLA office. The NCLA Administrative Assistant will then forward the payment request to the treasurer.

- If a speaker or presenter is to be paid, a contract is required for that individual.

- Make sure the contracts are clear about cancellation policies regarding your down payment, particularly if you have registration enrollment expectations. 


\section{Day of the Program}

- Set up your registration desk in a central location.

- Have printed name tags ready.

- Consider including coffee/juice/tea in the morning. Our program attendees were very disappointed that we did not serve coffee and water pre-workshop, particularly attendees who traveled from out of town.

- Set up a NCLA registration/membership services desk. Contact the NCLA Membership Chair for information.

- Check on computers, projectors, seating, etc., in rooms.

- Bring extension cords.

- Keep the phone numbers of the facility manager and technical support staff handy at all times.

- Be prepared for on-site registration.
- Have an evaluation form ready for your attendees.

- If the event is catered, have a section member check on the food in advance.

Afterwards

- Mail or fax copies of the invoices along with a check payment form to the NCLA Administrative Assistant. The office manager will forward the information to the NCLA Treasurer for payment.

- Compile the responses from the evaluation surveys and forward to the appropriate persons (Section Board members, NCLA Executive Board, Membership Chair)

- Keep relevant information handy to pass on to the next section Chair.
Directions to Moseley Center

Elon University

- $\quad$ Take Interstate $85 / 40$ to Exit 140 (University Drive). From southbound $85 / 40$, exit right and turn right. From northbound 85/40, exit right and turn left.

- At the first stoplight (shopping center entrance) turn right onto St. Mark’s Church Road.

- Follow this road for 2.6 miles. Note that the road's name changes to Williamson Ave. after you cross S. Church Street. You will cross railroad tracks as you enter the campus area.

- Turn right at the stoplight on Haggard Avenue.

- Turn left at the stoplight on N. O'Kelly Ave. Take the first left into the Visitors Parking Lot at Moseley Center.

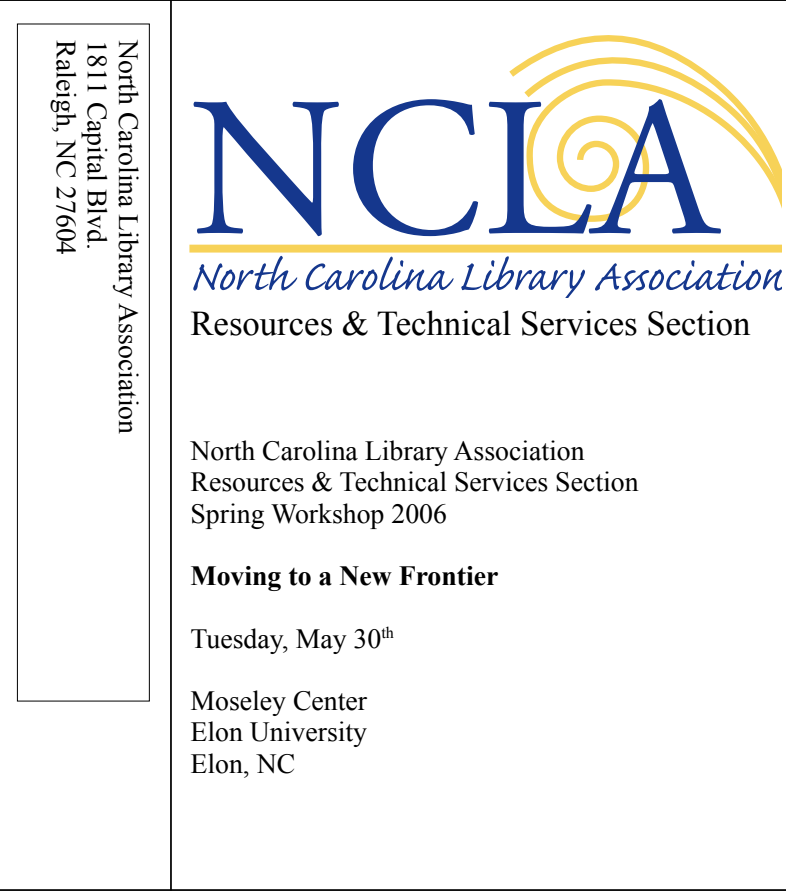

The Resources and Technical Services Section of the North Carolina Library Association presents its 2006 Spring Workshop, entitled:

\section{Moving to a New Frontier}

Location: Moseley Center, Elon University, Elon, NC.

Date: Tuesday, May $30^{\text {th }}$.

Time: 10 am to $3: 30 \mathrm{pm}$.

The workshop will include eight programs focusing on cataloging, acquisitions, collection development, and serials.

All interested persons are invited to attend, registration fees vary according to NCLA membership.

A box lunch is available for $\$ 8.00$.

\section{NCLA RTSS Spring Workshop Program}

Searching in Connexion Browser and Client

WorldCat Collection Analysis Service

What is FRBR?

Issues and Opportunities for Paraprofessionals

The Web in Our Libraries and Catalogs: a Ten-Year Retrospective

Roundtable on the Basics of Authority Control

E-Journals: What Five Years of On-the-Job Training Can Teach You

Find it! Reference Technology Trends

$* * * * * * * * * * * * * * * * * * * * * * * * * * * * * * *$

Detailed descriptions of NCLA RTSS Spring

Workshop programs may be found at:

http://www.nclaonline.org/rtss/

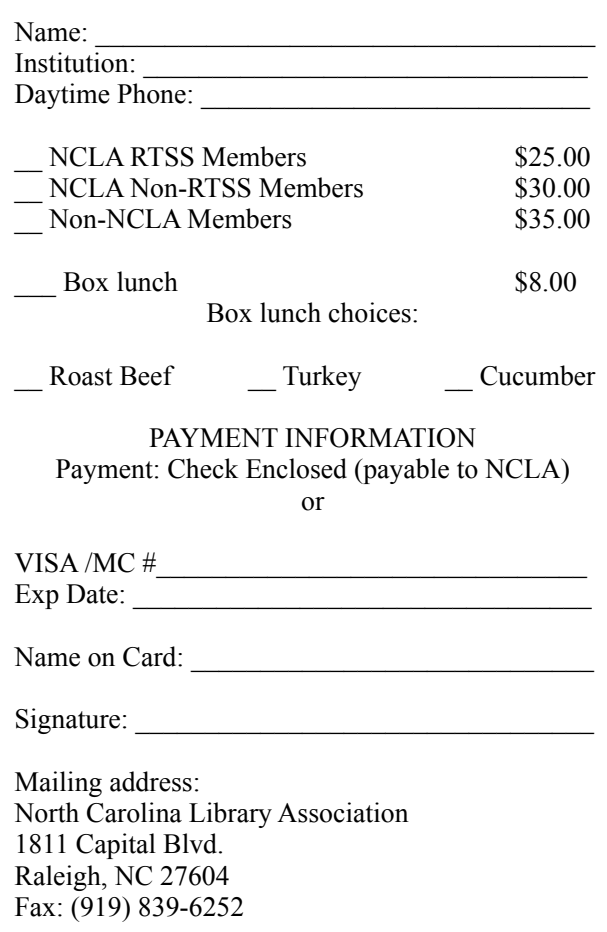

